\title{
$\mathrm{BGA}$ 교육 프로그램이 뇌 발달에 미치는 효과성 연구 -유아대상- \\ 홍양표 ${ }^{1}$, 백기자 ${ }^{*^{*}}$ \\ ${ }^{1}$ 한국좌우뇌교육개발연구소
}

\section{Research on the Effect of BGA Education Program on Brain Development -for kids-}

\author{
Yang-Pyo Hong ${ }^{1}$ and Ki-Ja Bak ${ }^{1^{*}}$ \\ ${ }^{1}$ Korean Research Institute of Corelation Brain Education Development
}

요 약 이 연구는 BGA 교육프로그램을 통하여 유아들의 뇌발달에 미치는 영향을 개인이 지닌 뇌신경 생리학적 지 표인 뇌파 측정을 이용하여 연구 하였다. 대상자는 2010년 7월에서 2010년 12월까지 S시, W시 유치원 원아 200명 (실험군 100 명, 대조군 100 명)을 기준으로 선정한 자료이다. BGA 교육 프로그램은 일주일에 3 회씩 6 개월 동안 진행 하였으며 1 회교육시간은 30 분 정도이다. BGA 교육 프로그램 적용 전과 후의 뇌발달 변화는 시계열 선형 분석을 통 하여 비교하였으며 연구 검증 결과. $\mathrm{BGA}$ 교육 프로그램을 적용한 원아들의 뇌기능에서 유의미한 차이를 보였다. 이 결과는 $\mathrm{BGA}$ 교육 프로그램이 유아들의 뇌 발달에 긍정적인 영향을 미쳤다고 본다.

\begin{abstract}
This study was to examine the effectiveness of BGA education program by observing the pre and post brainwave measurement results of about W, S city kindergarten kids 200 (experimental group 100. comparative group 100) subjects who have shown brain quotient, in between the months of Jul. 2010 and Dec. 2010. As the brainwaves are adjusted by timeseries linear analysis, the result confirmed the differences of both brain quotient. The result of the study suggest BGA education program possibility in positively affecting the subjects' brain development.
\end{abstract}

Key Words : BGA, Brain development, Brainwave, Brain quotient

\section{1. 서 론}

\section{1 연구의 필요성과 목적}

고도의 지식 정보화 시대에 살고 있는 이 시대는 창의 적인 두뇌 능력을 갖춘 전인적인 인간이 요구되고 있다. 창의적이고 전인적인 인간 양성을 위해서는 인간 두뇌의 전체적이고 조화로운 사용을 도와주는 교육이 필요하며 그러기 위해서는 두뇌의 기능 향상이 필요하다[1]. 유아 기는 뇌의 발달에 있어 결정적 시기이며, 유아기는 뇌의
가소성이 풍부한 시점이기 때문에 뇌의 학습기제에 기반 을 둔 체계적인 프로그램의 개발 및 적용이 강력하게 요 구되는 시기라고 설명하고 있다[2]. 그러나 한국의 유아 교육 실정은 과정중심을 통한 뇌 계발의 목적보다는 결 과 중심인 좌뇌 교육에 치중되어 지고 있다. 특히 어린이 집이 기하학적으로 늘어나고 시설과 교육이 유치원과 동 일시 되어가는 분위기가 조성되면서 많은 교육기관에서 원아 모집에 어려움을 겪게 되고 이로 인해 과정중심교 육을 해야 함에도 불구하고 부모들이 원하는 결과 중심

본 연구는 박사학위 논문을 요약한 내용임

"교신저자 : 백기자(brainbaik@hanamail.net)

접수일 11 년 07 월 15 일 
교육에 치우치고 있는 것이 현실이다. 결과 중심인 좌뇌 교육은 인성교육을 해야 하는 시기에 한쪽으로 편중된 뇌를 사용하게 될 것이고 어른으로 성장하여서도 인성 교육의 본질에서 멀어지며 창의성이 떨어지고 이는 더 낳아가 사회적인 문제가 될 것으로 보아진다[3]. 또한, 유 아들의 일상적인 행동이나 방식에 대한 적응능력과 전인 교육의 질을 향상시키기 위한 다양한 방법에 대해 논의 되고 있지만 뇌 발달의 관련된 효과성에 대해서는 부족 한 실정이다. 최근에는 뇌파 조절 기기의 활용과 관련하 여 이에 대한 객관적인 연구 방법과 결과의 계량화를 위 한 연구가 시도되면서 객관적인 검증이 시도되고 있다 [4]. 그러나 유아들을 대상으로 효과 검증으로 뇌파 측정 한 연구에 대한 경험적 증거는 미흡한 상태이다. 따라서 본 연구에서는 유아들을 대상으로 뇌 발달에 초점을 맞 춘 $\mathrm{BGA}$ 교육프로그램을 적용하고자 하며, 또한 $\mathrm{BGA}$ 교 육 프로그램이 이 유아들의 뇌기능에 어떠한 영향을 미 치는지를 실제 실험을 통하여 밝혀보는데 목적이 있다. 그리고 뇌파측정을 통하여 객관적이고 신경과학적인 방 법으로 파악하고자 한다.

\section{2 연구 가설}

본 연구에서는 유아들을 대상으로 뇌파를 측정하고 $\mathrm{BGA}$ 교육 프로그램을 적용하여 뇌기능을 향상 시킬 수 있는가를 실제 실험을 통해 밝혀보는데 목적이 있다. 위 와 같은 목적에 따라 본 연구에서 설정한 연구 가설은 다 음과 같다.

가설1, BGA 교육 프로그램을 적용한 실험군은 대조군 에 비해 자기조절지수에서 차이가 있을 것이다. 가설2, BGA 교육 프로그램을 적용한 실험군은 대조군 에 비해 주의지수에서 차이가 있을 것이다.

가설3, $\mathrm{BGA}$ 교육 프로그램을 적용한 실험군은 대조군 에 비해 항스트레스지수에서 차이가 있을 것이다.

\section{3 용어의 정리}

\subsection{1 뉴로피드백}

인간의 정신 상태를 반영하는 뇌파를 컴퓨터 모니터를 통해 관찰하고, 가장 이상적인 뇌파를 만들어내는 정신 상태를 스스로의 노력에 의해 유지하도록 학습하는 과정 이다. 뉴로피드백의 원리는 뇌파를 이용하여 뇌의 항상성 자기 조절 능력을 강화하여 뇌의 가소성을 향상시키는 기술, 다시 말해 자기 뇌를 보고, 듣고, 느끼면서 스스로 훈련 하는 것이다[5].

\subsubsection{BGA(Brain General Analysis)교육 프로그램}

유아들의 두뇌 발달 성향을 검사하여 영역별 기능들을 조정 통합하여 좌우뇌가 균형과 조화를 이루며 발달하도 록 도와주는 교육 프로그램이다.

본 연구에서는 홍양표가 개발한 교육 프로그램으로 좌 뇌 훈련 프로그램으로 추상력 훈련, 언어-사고력훈련, 수리력 훈련, 추리력 훈련, 우뇌 훈련 프로그램으로 협응 력 훈련, 구성력훈련, 시각통찰력 훈련, 지각 속도력 훈련 을 적용한다.

\subsection{3 뇌기능 지수}

한국정신과학연구소에서 개발한 뇌기능 분석 프로그 램(BQ Test)을 이용하여, 각 주파수 대역별로 측정한 뇌 파 수치들의 비율 분석을 통해 구한 지수들을 기반으로, 뇌의 기능을 종합 평가하는 지수이다[6]. 뇌기능 분석은 뇌파를 통해 뇌의 기능을 다각적으로 측정하는 프로그램 이다. 이 지수는 자기조절 지수, 기초율동 지수, 주의 지 수, 활성 지수, 정서지수, 항스트레스 지수, 좌·우뇌균형 지수, 브레인 지수의 8 가지 영역으로 구분되며 그것들의 하위지수로 54 가지의 지수들이 있다[7]. 본 연구에서는 유아들의 뇌기능 특성을 기반으로 선택하여 사용하였다. 또한, 한국정신과학연구소의 2 채널 시스템(channel system) 이동식 뇌파측정기(Neuro-Harmony)로 측정한 뇌기능을 종합적으로 판단하는 뇌기능 분석 프로그램(BQ Test)의 지수를 말한다. 뇌파측정은 두뇌기능 상태를 실시간 평가 할 수있는 매우 우수한 신경 과학적 검사법 이라할 수 있 다[8]. 표 1 참조.

[표 1] 뇌파측정을 통해 나타난 뇌기능의 특성

[Table 1] The Characteristics of Brain Quotient by Brain Wave Measurement

\begin{tabular}{|c|c|}
\hline 분 석 지 수 & 의 미 \\
\hline 자기 조절지수 & 자율신경계 조절 \\
\hline 주의지수 & 뇌의 각성 정도 판단 \\
\hline 항 스트레스지수 & 스트레스저항정도 \\
\hline
\end{tabular}

\section{2. 연구 방법}

\section{1 연구 설계}

본 연구는 유아들의 뇌발달에 BGA 교육 프로그램이 미치는 영향을 분석하기 위한 전후 설계 실험 연구이다. 
[표 2] 실 험 설 계

[Table 2] Research Design

\begin{tabular}{|c|c|c|c|}
\hline & 사전조사 & 교육적용 & 사후조사 \\
\hline 실험군 & $\mathrm{Ye} 1$ & $\mathrm{x}$ & $\mathrm{Ye} 2$ \\
\hline 대조군 & $\mathrm{Yc1}$ & & $\mathrm{Yc} 2$ \\
\hline
\end{tabular}

$\mathrm{x}$ BGA 교육 적용

\section{2 연구 대상}

2010년 7월부터 2010년 12월까지 S시, W시 유치원 원 아 200 명(실험군 100 명, 대조군 100 명)의 뇌파를 검사하 여 $\mathrm{BGA}$ 교육 전과 훈련 후의 뇌기능의 변화를 보고자 하였다.

실험군은 유치원 수업에서 $\mathrm{BGA}$ 교육을 실시한 원아 들이며 대조군은 비적용 원아들로써 사전, 사후에 대한 뇌파를 측정 하여 비교하였다. 대상자의 일반적 특성은 학기 초에 나이, 유아의 인지능력 등을 고려하여 균등한 배정을 하기 때문에 동질 집단으로 구성되어 있다고 볼 수 있다.

[표 3] 연구 대상의 구체적 분포

[Table 3] Detailed Distribution of the Subjects

\begin{tabular}{|c|c|c|}
\hline & 실 험 군 & 대 조 군 \\
\hline 남 & 49 명 & 54 명 \\
\hline 여 & 51 명 & 46 명 \\
\hline 나이 & $5.34($ 세) & $5.25($ 세 $)$ \\
\hline 전체 & 100 & 100 \\
\hline
\end{tabular}

\section{3 연구도구}

\subsection{1 뇌파측정기}

본 연구에 사용된 측정도구는 '한국정신과학연구소' 에서 개발한 2 channel system 이동식 뇌파측정기 이다. 이 측정도구는 휴대용 뇌파 측정 및 훈련겸용기기이다. 이 도구는 비침습형 헤드밴드 형태로 측정자 친화적인 휴대용 뉴로피드백 시스템 뇌파 측정 장치(뉴로하모니) 이다. 뉴로하모니는 2 채널 뇌파 측정기를 기본으로 단극 유도법과 쌍극유도법을 혼합하여 사용하고 있다. 진폭의 세기는 전압 $(\mu \mathrm{V})$ 으로 나타내어 활성도(activity)값으로 사 용되었다. 한국정신과학연구소에서 개발한 뉴로피드백은 2 channel, 건식전극, 귓불전극을 한 개 사용, 시스템은 잘 알려져 있는 뇌파 측정기인 Grass System(USA)과의 상관계수가 .916(p<.001)으로 나타나 신뢰도가 입증된 바 있다[1].

\subsubsection{BGA 검사}

$\mathrm{BGA}$ 검사는 로저 스펠리 박사의 “분할 뇌 이론”을 기 초로 뇌에 관해 본격적으로 연구한 [9]의 연구를 바탕으 로 한국좌우뇌교육개발연구소에서 1990년 초부터 수정 보완하여 개발하기 시작하였다. $\mathrm{BGA}$ 검사는 $\mathrm{BPI}(\mathrm{Brain}$ Priority Indices)를 수정 보완하여 좌뇌와 우뇌 기능중 어 느 영역이 우위에 있는지, 어떠한 영역과 기능들이 뇌 발 달의 성향을 주도하는지와 뇌발달 에 맞춘 검사지로 정 립되었다. 이로써 한국인에 맞는 검사 도구를 얻게 되었 으며 그 프로그램의 명칭을 "BGA 검사라고 명명하였다 [10]. 본 연구에서의 $\mathrm{BGA}$ 검사지수는 뇌 종합 검사의 항 목별 지수를 의미한다. 항목별 지수는 BGA지수, 좌뇌 지 수, 우뇌 지수, 추상력 지수, 언어사고력 지수, 수리력 지 수, 추리력 지수, 협응력 지수, 구성력, 시각 통찰력 지수, 지각 속도력 지수를 말한다. 이 검사는 도구의 신뢰도 계 수는 .830으로 나타났다[11]. 표 4는 하위요인 신뢰도 분 석이다.

[표 4] 신뢰도분석

[Table 4] Reliability Analysis

\begin{tabular}{cccc}
\hline 문항 & $\mathrm{M}$ & $\mathrm{SD}$ & 계수 \\
\hline 추상력 & 22.71 & 10.58 & .816 \\
\hline 언어사고력 & 22.01 & 9.64 & .816 \\
\hline 수리력 & 27.94 & 11.06 & .823 \\
\hline 추리력 & 23.63 & 11.75 & .808 \\
\hline 좌뇌합산 & 96.28 & 30.04 & .798 \\
\hline 협응력 & 15.89 & 8.33 & .824 \\
\hline 구성력 & 28.66 & 10.97 & .810 \\
\hline 시각통찰력 & 18.52 & 11.84 & .826 \\
\hline 지각속도력 & 19.76 & 7.90 & .823 \\
\hline 우뇌합산 & 82.82 & 25.98 & .792 \\
\hline Alpha계수=.830, $\mathrm{N}=200$ & &
\end{tabular}

\section{4 실험 방법}

$\mathrm{BGA}$ 교육 프로그램을 실시하는 교사는 8시간의 집중 교육과 매월 4시간의 보수교육을 받으며 직접 교육한 자 료를 검사하면서 피드백 시키는 방법으로 진행되었다. 교 육은 그림 1 과 같은 교재를 활용하였으며, $\mathrm{BGA}$ 교육 프 로그램은 일주일에 3 회씩 6 개월 동안 진행하며 1 회교육 시간은 30 분 정도이다. 표 5 는 $\mathrm{BGA}$ 교육 프로그램의 실 예이며, 영역별로 구체적으로 나누어져있다. 지시문과 활 동 목표와 활동 방법등에 대하여 자세히 서술되어 있다. 시간대는 유치원의 하루일과 중 두뇌활동이 활발한 오전 에 실시하였다. 실험의 오염요인(새로운 사람과, 새로운 
진행으로 유아들이 산만해지는 것 등)을 통제하기 위하 여 원아들과의 소통이 원활한 담임선생님을 선택하였으 며, 실험자는 관찰자로서 참여하여 문제점을 보안하며 실 험의 최대효과를 내고자 노력하였다.
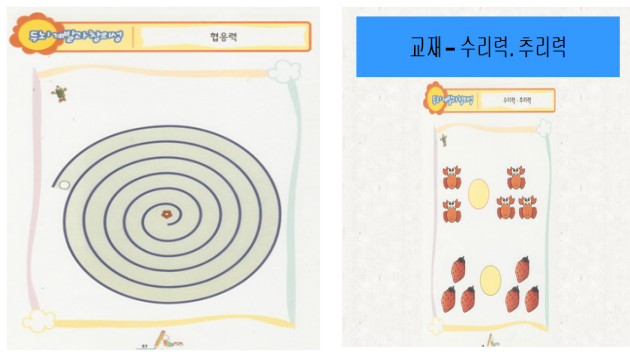

[그림 1] $\mathrm{BGA}$ 교육 프로그램

[Fig. 1] BGA Education Program

[표 5] BGA 교육 프로그램

[Table 5] BGA Education Program

\begin{tabular}{c|l}
\hline 내용 & \multicolumn{1}{|c}{ 지시문 } \\
\hline \multirow{2}{*}{ 추상력 } & $\begin{array}{l}5 \text { 가지 그림 중에서 나머지 4개와 서로 어울리지 않 } \\
\text { 는 것 하나를 골라내어 표를 하여라. }\end{array}$ \\
\hline 언어사 & $\begin{array}{l}\text { 네모 칸 안에 있는 그림의 이름과 똑같은 소리로 } \\
\text { 시작되는 그림을 골라 } \bigcirc \text { 표 하도록 한다. }\end{array}$ \\
\hline \multirow{2}{*}{ 수리력 } & $\begin{array}{l}\text { 네모 칸 안에 있는 그림의 개수를 세어보고 그 수 } \\
\text { 가 가장 큰 것을 골라내어 표 하여라. }\end{array}$ \\
\hline 추리력 & $\begin{array}{l}\text { 그림들이 일정한 규칙에 따라 왼쪽에서 오른쪽으 } \\
\text { 로 배열되고 있다. \{ \}안에 들어갈 알맞은 모양을 } \\
\text { 찾아내어 요 표 하도록 한다. }\end{array}$ \\
\hline
\end{tabular}

\section{5 자료 분석 방법}

자료 분석은 SPSS 12.0 통계프로그램을 이용하여 분 석하였다. $\mathrm{BGA}$ 교육 전과 후 실험군과 대조군의 집단 간 의 뇌기능차이를 알아보기 위하여 공분산 분석 (ANCOVA)을 이용하였다. 측정도구 신뢰도 검증은 Cronbach Coefficient alpha를 산출하였고, 모든 자료에 대하여 평균과 표준편차를 산출하였으며, 유의수준을 $95 \%$ 수준에서 검정하였다.

\section{3. 연구 결과 및 가설 검증}

연구대상자의 일반적 특성에 대한 동질성 검증은 뇌기 능에 대하여 종합적인 값을 보여주는 $\mathrm{BQ}$ 테스트의 뇌기 능 점수와 $\mathrm{BGA}$ 두뇌 종합검사의 영역별 점수를 사용하 여 두 집단 간에 비교 하여 동질성 검증을 하였다. $\mathrm{BGA}$
점수는 두 집단 간에 통계적으로 유의한 차이를 보이는 특성이 없어 두 집단은 동질한 집단으로 구성되었다. 뇌 기능 지수에서는 산만도만 제외하고 동질 하였다.

\section{1 가설 검증(자기조절지수 - 주의지수 - 항 스 트레스지수)}

"BGA 교육 프로그램을 적용한 실험군은 대조군에 비 해 자기조절지수에서 차이가 있을 것이다.” 라는 가설을 검증하기 위하여 공분산 분석을 한 결과 표 6 과 같이 자 기조절지수와 항스트레스지수에서 유의미한 차이를 보였 다. 주의지수에서는 하위지수 긴장도와 산만도에서 유의 미한 차이를 보였다. 자율신경계의 조절능력을 보는 자기 조절지수와 정신적, 육체적인 긴장도와 각성 정도를 파악 하는데 사용되는 주의지수(하위지수 긴장도, 산만도), 스 트레스를 이겨낼 수 있는 능력을 나타내는 항 스트레스 지수(좌, 우),에 대한 검증 결과이며 그 결과는 표 6에 제 시하였다.

[표 6] 자기조절, 주의, 항 스트레스지수 공분산분석

[Table 6] ANCOVA of Selfregulation, Attention, Antistress Quotient

\begin{tabular}{|c|c|c|c|c|c|}
\hline & $\begin{array}{c}\text { 제 III 유형 } \\
\text { 제곱합 }\end{array}$ & $\begin{array}{c}\text { 자유 } \\
\text { 도 }\end{array}$ & 평균제곱 & $F$ & $p$ \\
\hline 자기조절 & 364.049 & 1 & 364.049 & 1.343 & .248 \\
\hline 집단 & 6913.577 & 1 & 6913.577 & 25.513 & $.000^{* * *}$ \\
\hline 긴장도(좌) & 66.498 & 1 & 66.498 & .260 & .610 \\
\hline 집단 & 4228.423 & 1 & 4228.423 & 16.560 & $.000^{* * *}$ \\
\hline 긴장도(우) & 177.686 & 1 & 177.686 & .702 & .403 \\
\hline 집단 & 4593.324 & 1 & 4593.324 & 18.156 & $.000^{* * *}$ \\
\hline 산만도(좌)) & .019 & 1 & .019 & .015 & .902 \\
\hline 집단 & 44.738 & 1 & 44.738 & 34.991 & $.000^{* * *}$ \\
\hline 산만도(우) & .002 & 1 & .002 & .001 & .971 \\
\hline 집단 & 70.311 & 1 & 70.311 & 49.163 & $.000^{* * *}$ \\
\hline 항스트(좌) & 67.118 & 1 & 67.118 & .212 & .646 \\
\hline 집단 & 5681.177 & 1 & 5681.177 & 17.906 & $.000^{* * *}$ \\
\hline 항스트(우) & 120.500 & 1 & 120.500 & .382 & .537 \\
\hline 집단 & 6158.821 & 1 & 6158.821 & 19.547 & $.000^{* * * *}$ \\
\hline
\end{tabular}
${ }^{*} p<.05,{ }^{* *} p<.01,{ }^{* * *} p<.001$

두 집단 간의 사후검사 점수 차이가 유의한가를 알아 보기 위하여 공분산분석으로 분석한 결과 표 6 과 같이 자 기조절지수 $F=25.513, p=.000$, 긴장도(좌) $F=16.580$, $p=.000$, 긴장도(우) $F=18.156, p=.000$, 산만도(좌,우) $F=34.991, p=.000, F=49.163, p=.000$ 로 유의미한 차이가 있었다. 그리고, 항 스트레스(좌)에서 $F=17.906, p=.000$, (우) $F=19.547, p=.000$ 의 유의미한결과를 나타냈다. 
두 집단의 주의지수·항 스트레스지수·좌우뇌균형 지수의 평균, 표준편차, 조정된 훈련 후 점수는 표 7과 같다.

[표 7] 두 집단의 평균, 표준편차, 조정된 훈련 후 점수 [Table 7] Comparison of M, SD, Between Experimental and Control Groups

\begin{tabular}{|c|c|c|c|c|c|c|c|}
\hline \multirow[t]{2}{*}{ 평가구분 } & \multirow[t]{2}{*}{ 집단 } & \multicolumn{2}{|c|}{ 훈련 전 } & \multicolumn{2}{|c|}{ 훈련 후 } & \multicolumn{2}{|c|}{$\begin{array}{l}\text { 조정된 } \\
\text { 훈련 후 }\end{array}$} \\
\hline & & $M$ & $S D$ & $M$ & $S D$ & $\bar{M}$ & $S E$ \\
\hline \multirow{2}{*}{ 자기조절 } & 험군 & 67.42 & 20.33 & 74.22 & 16.86 & 74.12 & 1.65 \\
\hline & 대조군 & .23 & .88 & 62.22 & 16.08 & 62.33 & 1.65 \\
\hline \multirow{2}{*}{ 긴장(좌) } & 실험군 & 24.04 & 10.81 & 20.92 & 10.72 & 20.94 & 1.60 \\
\hline & 대조군 & 23.34 & 11.29 & 30.16 & \begin{tabular}{|l|l|}
19.84 \\
\end{tabular} & 30.14 & 1.60 \\
\hline \multirow{2}{*}{ 긴장(우) } & 실험군 & 24.33 & 10.95 & 21.20 & 9.52 & 21.24 & 1.59 \\
\hline & 대조군 & 23.49 & 9.63 & 30.87 & 20.36 & 30.84 & 1.59 \\
\hline \multirow{2}{*}{ 산만(좌) } & 실험군 & 2.27 & 1.87 & 99 & 74 & .99 & .11 \\
\hline & 대조군 & 1.67 & 1.03 & 1.96 & \begin{tabular}{|l|}
1.41 \\
\end{tabular} & 1.96 & .11 \\
\hline \multirow{2}{*}{ 산만(우) } & 실험군 & 2.27 & 1.79 & 1.02 & 67 & 1.02 & .12 \\
\hline & 대조군 & 1.74 & 1.01 & 2.23 & 1.56 & 2.23 & .12 \\
\hline \multirow{2}{*}{$\begin{array}{l}\text { 항스트 } \\
\text { (좌) }\end{array}$} & 실험군 & 67.24 & 12.59 & 70.47 & 12.27 & 70.44 & 1.78 \\
\hline & 대조군 & 68.26 & 12.85 & 59.75 & 21.94 & 59.78 & 1.78 \\
\hline \multirow{2}{*}{$\begin{array}{c}\text { 항스트 } \\
\text { (우) }\end{array}$} & 실험군 & 66.88 & 12.51 & 70.01 & 11.04 & 69.97 & 1.78 \\
\hline & 대조군 & 68.10 & 11.08 & 58.82 & 22.50 & 58.86 & 1.78 \\
\hline
\end{tabular}

이 결과는 뇌기능 지수가 사전에는 동질 하였으나 사 후에는 집단 간 차이가 났다는것을 의미하며, 실험군의 뇌기능 점수가 높게 나타나 $\mathrm{BGA}$ 교육의 효과가 뇌기능 에 긍정적인 영향을 미쳤다고 본다. 긴장도나 산만도는 점수가 낮아질수록 바람직하다.

\section{4. 결론 및 논의}

연구 결과는 다음과 같다. 첫째, $\mathrm{BGA}$ 교육 프로그램 을 적용한 실험군의 자기조절지수, 주의지수, 항 스트레 스지수에 긍정적인 영향을 미쳤다. 자기조절지수와 주의 지수의 하위지수인 긴장도, 산만도에서 유의미한 변화가 나타났다. 또한 항 스트레스지수에서도 유의미한 변화가 확인되었다. 자기조절지수의 상승은 유아들의 활동리듬 을 통제할 수 있으며 자기조절능력 향상과 무관하지 않 으며, 이 결과는 유아들에게 전두엽의 베타파를 활성화 시켜 뇌의 활동성을 향상시켰다고 본다[12]. 주의지수 (Attention Quotient)가 높게 나타난다면 뇌가 맑게 각성 되어 주의력이 좋아지며, 면역 기능이 높은 상태에 있다 는 것을 의미한다. 육체적 긴장 정도를 파악하는데 사용 되는 델타(ס)파의 수준인 긴장도와 정신적 긴장 정도를 파악하는데 사용되는 고 베타( $\beta$ )파의 산만도 지수가 유
의미하게 향상되었다는 것은 신경이 안정되고, 주의집중 력이 향상되었음을 의미하며 본 연구의 결과와 일치하였 다[13]. 항스트레스지수의 긍정적인 변화는 BGA 교육 프 로그램 적용 후 정신적 긴장, 불안, 흥분상태 뿐만 아니라 육체적인 긴장이나 질병에 대한 대응능력이 높아 졌다는 것을 의미한다. 이는 훈련 후 유아들이 가정이나 유치원 생활에 대하여 스트레스를 덜 받으며, 받았다손 치더라도 대처능력이 원활해 졌다고 볼 수 있다[14]. 둘째, BGA 교 육 프로그램이 뇌기능 지수에 미치는 긍정적인 영향은 유아들을 대상으로 경험과 학습이란 환경적 요인이 더 중요하다는 결론으로 두뇌발달촉진에 긍정적인 영향을 줄 수 있을 것이다. 실험결과를 보았을 때 뇌의 가소성은 뇌가 유전자에 의해 정해진 대로 만들어진 틀로 딱딱하 고 고정된 시스템이 아니라 생명 활동을 하는 동안에 그 환경과의 상호작용을 통하여 자기의 구조를 바꿀 수 있 는 유연한 시스템이라는 것을 증명하여 주었다[2]. 오늘 날 유아들에 대한 정신적 건강과 행복 증진을 위한 프로 그램 개발은 시기적으로도 절실히 요구되고 있는 과제이 다라고 강조한 $[15,16]$ 의 연구를 뒷받침한 결과이다. 결 론적으로 BGA 교육프로그램이 유아들에게 미치는 긍정 적인 영향은 경험과 학습이란 환경적 요인의 중요성과 상호작용을 통하여 유아교육의 방향성을 제시하였다고 본다.

또한, 이 연구는 기존의 설문지와 문제풀이 방식만을 통한 간접 분석결과와는 달리 유아들의 학습활동이나 정 신작용을 객관화하기 위하여 개인이 지닌 뇌신경 생리학 적 지표를 이용하여 신경과학적 연구방법을 적용한 것에 의의가 있다고 할 수 있다. 연구의 제한점과 제언으로는 $\mathrm{BGA}$ 교육 프로그램을 적용한 후속연구에서는 뇌 발달과 관련하여 좌우뇌 균형과 다방면의 발달에 기인한 지표 적용이 필요하다고 보며 본 연구결과들이 다양한 접근을 통하여 재현될 수 있어야 할 것이며, $\mathrm{BGA}$ 교육 프로그램 에 대한 연구 자료가 축척되고 평가될 필요가 있을 것이 다.

\section{References}

[1] Y. J. Kim, "Development of Brain Circulation Learning Model Based on EEG Analysis of Learning Activities". Unpublished Doctoral Dissertation, Seoul National University, 2000.

[2] J. N. Giedd, P. M. Thompson, E. R Sowell, \& A. W.Toga Structural MRI and Brain Development, International Review of Neurobiology, Neuroimaging, 
Part B 67, pp. 285-323. 2005.

[3] Y. M. Kim, "Research in Brain Development and its Implications for Early Childhood Education”, 26(4), pp. 31-49, 2006.

[4] P. Kropp, "On the Pathophysiology of Migraine-links for Emprically Based Treatment with Neurofeedback". Applied Psychophysiol Biofeedback, 27(3), 203-213. 2002.

[5] D. K. Kim, H. B. Park, Y. W. Ahn, "Neurofeedback Principles and Clinical Application", 13(2), pp.93-98, 2005.

[6] P. W. Park, " Foundation of Neurofeedback" Seoul: Korea Research Institute Jungshin Science. 2005a

[7] Y. E. Byun, "The Effect of Neurofeedback Training on Age and Sex differences Groups in Adolescence", Unpblished Doctoral Dissertation, Seoul Buddhism University, 2010.

[8] D. S. Kim, C. O. Choi, "Electroencephalogram Inspection learning". Seoul: Korea medical, 2001.

[9] L. M. Knolle, "Differences between Korean and American middle school students in cognitive function" (Y. H. Go Ed.) Aju University, 9 pp.153-162 1987.

[10] Y. P. Hong, "A Study of the Left and Right Cerebral on the Kids Brain Corelation Development, Korean Academy Practical Human Welfare, pp.279-294, 2010.

[11] Y. P. Hong, " Research on the Correlation of BGA Education Program and Brain Development, Unpublished Doctoral Dissertation, Seoul Buddhism University, 2011.

[12] Peniston, E. G., Marrinan, D. A., Deming, W. A. \& Kulkosky, P. J. " The Possible Meaning of the Upper and Lower Alpha Frequency Ranges of Cognitiveand Creative Tasks, International Journal of Psychophysiology, 26, pp. 77-97. 1993.

[13] J. F. Lubar., "Evalulation of the Effectiveness EEG Neurofeedback Training for ADHD in a Clinical Setting as Measured by Changes in T.O.V.A. Scores Behaviorral Rating, and WISC-R Performance", Biofeedback \& Self-rregulation, 20, pp. 83-99. 1995.

[14] K J., Bak, "A Study on the Effects of Neurofeedback Training on the Resistance Stress of Children", The Korea Acdemia-Industrial Cooperation Society, 11(3), pp. 1066-1071, 2010

[15] S. O. Jang, "The Effect of Neurofeedback Training on Development of Infants' Brain Function and Intelligence" Unpublished Doctoral Dissertation, Seoul Venture and Information University. 2008.

[16] S. K., Ahn, K .J. Bak, "The Effect of Brainwave Training on Students' Acadamic Achievement \&
Ability of Resisting Stress), - for the Primary Student The Korea Acdemia-Industrial Cooperation Society, 10(10)), pp. 2952-2958, 2009.

\section{홍 양 표(Yang-pyo Hang)}

[정회원]

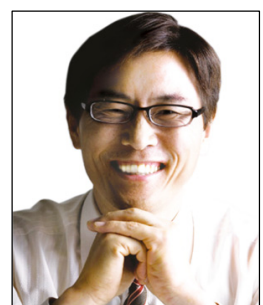

- 2000년 2월 : 명지대학교 교육대 학원(교육학 석사)

- 2011년 8월 : 서울불교대학원 대 학교 뇌 과학 박사(뇌 과학 전공)

- 2000년 3월 2008년 2월 : 명 지대 학원 겸임 교수

- 2003년 3월 현재 : 한국좌우 뇌교육계발연구소장

- $\mathrm{BGA}$ 교육학회 회장

<관심분야>

뇌과학, 뉴로피드백, 좌우뇌 교육

백 기 자(Ki-ja Bak)

[정회원]

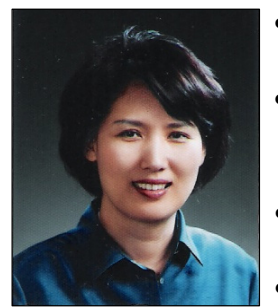

- 2002년 2월 : 중앙대학교 사회개 발 대학원(보건학석사)

- 2008년 2월 : 서울벤처정보대학 원 대학교 경영학박사(뇌과학 전 공)

- 2005년 6월 2007년 8월 : 호 원대학교 겸임 교수

- 2009년 2월 현재 : 서울불교 대학원대학교 초빙교수

- 2011년 2월 현재 : 서울벤처정보대학원대학교 겸임 교수

<관심분야>

뇌과학, 뉴로피드백, 자기주도 학습 